\title{
Causes of Affecting the Flow of Material and Energy in rivers Taking Longji Terraces as an example
}

\author{
Kaijie Wang ${ }^{1}$, Delan $\mathrm{Xu}^{1, *}$, and Xuelian $\mathrm{Zhu}^{1}$ \\ ${ }^{1}$ College of Tourism \& Landscape Architecture, Guilin University of Technology, Guilin 541004, China
}

\begin{abstract}
In order to explore the reasons that affect the flow of material and energy in the river, the Longji terraces are used as the research area, and the methods of field investigation and geospatial information technology are used to carry out research. The results show that human activities, vegetation coverage and the establishment of reservoirs are all factors that affect the flow of material and energy in the river.
\end{abstract}

\section{Introduction}

From human contact with water to application of water, there is an inseparable and important relationship between humans and water. People and water are closely related, the evolution of water and human life style, the progress and influence of water environment management technology, and the conflict and influence of water in history ${ }^{[1]}$. The use, management and control of water are closely related to human activities, and various problems caused by water quality are also the impact of human activities on water during the process of water use. We can learn from the experience of the historical process of water and human activities to reduce water pollution caused by human activities in the scenic area.

Since the 1970s, with the development of globalization, environmental problems have become increasingly prominent, among which water-related problems have gradually become prominent, such as water shortages, deterioration of water quality, and water environmental pollution ${ }^{[2]}$. Global warming, the increase of human activities, large-scale water resources crisis and water environmental pollution have become problems faced by countries all over the world. Human activities have aggravated the eutrophication process of water bodies and the seriousness of water pollution. The rivers in the scenic area are relatively well protected, but with the development of tourism and the continuous improvement of people's living standards, tourists enjoy more and more living consumption. The activities of local residents to cater to the needs of tourists also have a certain impact on the water quality of the rivers in the scenic area. influences. The Longji Terraces Scenic Area has continued to develop, and tourists have increased. The production and lifestyle of tourists and local residents have changed the physical and chemical properties of the river in the scenic area, affected the river mechanism, and changed the water quality. This research further provides a basis and foundation for the sustainable development of Longji Terraces by exploring the impact of specific human activities in the scenic area on the river.

\section{Materials and Methods}

\subsection{Overview of the study area}

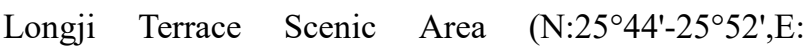
$\left.110^{\circ} 06^{\prime}-110^{\circ} 10^{\prime}\right)$ is located in Longsheng Town, Longsheng County, Guangxi Zhuang Autonomous Region,including Jinkeng Hongyao Terraces, Longji Ancient Zhuangzhai Terraces and Pingyao Beizhuang Terraces are two major scenic spots. The climate is a subtropical monsoon climate, with a lot of precipitation, with an annual precipitation of up to $1600 \mathrm{~mm}$ and a small amount of evaporation. Plenty of precipitation and abundant water resources.

There are more than 50 large and small rivers in the scenic water system, of which the Jinjiang River is the largest water system. The basin area can reach $180 \mathrm{~km} 2$, the annual average flow is $6.5 \mathrm{~m} 3 / \mathrm{s}$, and the river slope is $4.1 \%{ }^{[3]}$.

Small rivers such as Xiaozhai River, Dazhai River and Wengliu River flow into Jinjiang River, and the rainwater collection area is $84.9 \mathrm{hm}^{2}$. After Jinjiang River and Baishui River merged into Hepingxu, they were called "Heping River". The Heping River flows through Heping, Rixin, and Longsheng, and merges into the Sangjiang River in the west of the county seat. See Figure 1 for details. Natural precipitation and forest runoff are the main sources of water supply for the scenic area. The research river is located in the Longji terraces. It is an important part of the scenic area's ecosystem and the main source of water for the local aborigines. The river runs through the entire scenic area and the houses are built on the river.(Fig.1)

\footnotetext{
$\overline{{ }^{*} \text { Corresponding author:1061189751@qq.com }}$
} 


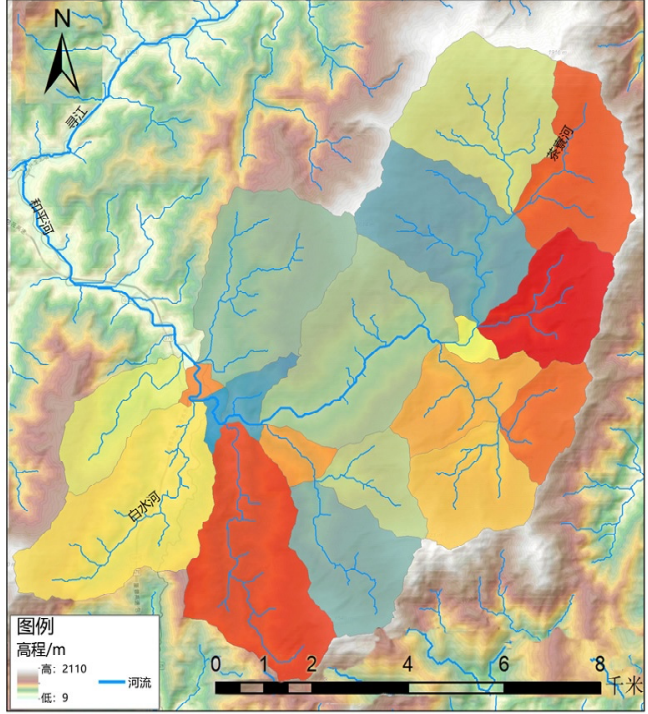

Fig. 1. Research The river basin map in the scenic area

\subsection{Data collection and processing}

In order to explore the impact of human activities on river water quality, the researchers set up multiple collection points in the rivers of the study area to collect three bottles of water from the origin of the river to prevent accidental collection of three bottles of water at one point, mark them, go down the river, and collect them in sequence.In order to make the data more accurate, it is collected intensively in places with dense residential buildings, tourist gathering places, and poultry and livestock gathering places. The collected water was immediately sent to the laboratory for water quality and nutrient analysis. With reference to the National Surface Water Environmental Quality Standard (GB3838-2002), the impact of human activities in scenic areas of ethnic minorities on river water quality was studied through the analysis of water quality and nutrient components.(Fig.2)

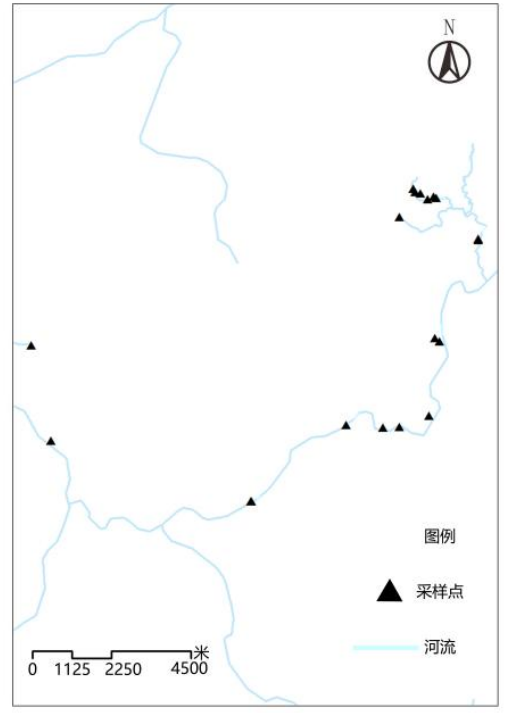

Fig. 2. Sampling point location map

\section{The impact of human activities on water quality}

\subsection{Tourist activities}

The Longji Terraced Fields Scenic Area is a perfect combination of natural landscape, farming civilization, spiritual culture and entertainment etiquette among ethnic minorities, and is the birthplace and place of agricultural cultural heritage. Therefore, a large number of tourists from all over the world come here every year. As the popularity of the Longji Terraces Scenic Area continues to expand, the number of tourists received by the scenic area is also increasing, and tourists' demand for water is increasing. Wu Zhongjun ${ }^{[5]}$ and others also mentioned in their research results that the conflict between tourists and water in the Longji Terraces Scenic Area is increasing day by day. Local homestays and restaurants have problems such as grabbing water from terraces and draining domestic sewage into rivers. When various grand events are held in the Longji terraced villages, the number of tourists has increased rapidly, and environmental damage such as littering and smoking has only increased. Less. The littering of cigarette butts, bottles, plastic bags and other garbage was washed into the river by rain because it was not treated in time, causing changes in the river's water quality. In addition, the wanton discharge of domestic sewage from the hotel accelerated the deterioration of the water quality. Tourist activities also have a certain impact on the water quality of the river.

\subsection{Aboriginal activities}

The aborigines of Longji Terraces are composed of Dong, Miao, Yao, Zhuang and other ethnic minorities. All ethnic groups live in harmony and have a unique village culture. The Dong people have a native diet with a rice-fish-duck symbiosis system, worshiping nature and a tree god culture; Yao people have traditional folk songs, singing folk songs, and traditional ethnic festivals such as the Panwang Festival, and their costume culture is also a highlight; the Miao culture has a spiritual fate. It features a lot of folk literature, and the history of the development of the costume culture of the Miao nationality is also very long. As a large ethnic group in the Guangxi Zhuang Autonomous Region, the Zhuang nationality has a rich and detailed material culture. For people who live in cities far away from the countryside for a long time, primitive and simple ethnic characteristics and traditional folk customs are the main reasons why Longji Terraces attract tourists. With the continuous publicity, expansion and development of the scenic area, the local aborigines began to build homestays to develop tourism. The villagers'water basically comes from spring water in the mountains, and the water quality is clean and pollution-free. After the tourism industry began to develop, in order to meet the needs of tourists, villagers began to use plastic pipes and iron pipes to draw water and drain and grab water from farmland. The construction of homestays and the excavation of 
mountains ${ }^{[6]}$ also caused damage to the Longji terraces and forests, and the water filtration process was damaged to a certain extent. Pollution of the water environment and changes in water quality and nutrients. B\&Bs and inns began to divert water from mountain streams that used to irrigate farmland. This conflicts with terraced fields. The water utilization rate is low, water resources are wasted, and the conflict between people and fields is increasing.

\subsection{Water demand}

Take the Ping'an Terrace Scenic Area as an example. Since the road was built in 1999 , the annual number of tourists has reached 14,099; in 2000, the number of tourists reached 27,542; in 2018, the Longji Scenic Area received 1,453,500 tourists. From 1999 to the end of 2018, the Longji Terraces Scenic Area received a total of $9,436,700$ tourists $^{[7]}$. The number of tourists is increasing year by year, and the water consumption is also increasing year by year. Considering that the water used by the aboriginal people in the scenic spot mainly includes domestic water, livestock water and other water, the quota analysis method is used to predict and calculate the domestic water demand. According to relevant data, the living standard of the residents in the scenic spot will increase in 2020, and the water standard and water demand will increase. Factors, the per capita comprehensive water consumption of the aborigines in the scenic area is $120 \mathrm{~L} /$ day, and the water consumption of livestock is $20 \mathrm{~L} /$ head. (According to the survey, the large-scale livestock breeding in the scenic area is reduced, mainly pigs and cattle). 10\% calculation. There are currently 9,000 residents in the scenic area. According to the current population growth rate, the aboriginal population will be 9,564 by the end of 2020 . By the end of 2020, the number of tourists will reach 1.5 million, calculated as half of the tourists spend the night in the scenic spot. Calculated on the basis of 1,200 livestock, by the end of 2020, the domestic water demand of the scenic spot is about $462,600 \mathrm{~m} 3$ (under standard pressure, $1 \mathrm{~L}=0.001 \mathrm{t}$ water; $1 \mathrm{t}=1 \mathrm{~m}^{3}$ ). According to statistics, the agricultural water demand is about $3,151,300 \mathrm{~m}^{3}$.

\subsection{Vegetation cover and land use}

With the development of the tourism industry, the number of tourists to the Longji Terraces instantly rose to three to ten times that of the aborigines. Due to the growing economic needs of local residents and tourists' yearning for natural beauty, the number of self-built houses and homestays around the river has increased. Whether land use and vegetation cover have changed. What are the impacts of the tourism development of the Longji Terraces Scenic Area on its vegetation coverage and land use methods are worthy of our discussion and research.

\subsubsection{Vegetation cover}

According to statistics, the forest coverage rate of the scenic area can reach $68.75 \%$, accounting for more than half of the vegetation coverage rate of the entire scenic area. It is mainly composed of economic timber forests and less shelter forests. The forest is mainly secondary tree species, without mature and over-mature forests. The grassland coverage rate reaches $29.72 \%$, the vegetation level is clear and abundant, and the resources are abundant.

The Longji terraces have always followed the model of mountain forest-village-terraced fields. The rivers originate from the Longji terraced forests. The water quality is clear and clean. It is the main source of water for local residents' daily life. The coverage rate of subtropical vegetation in the scenic area is relatively high. Subtropical broad-leaved forests are mostly at an altitude of $800-1300 \mathrm{~m}$, and economic forests occupies a small part; most of them are broad-leaved forests such as fir and tung trees below $800 \mathrm{~m}$. The abundant river water is also one of the reasons for the suitable climate of the Longji terraces. However, development will inevitably lead to destruction. The construction and increase of homestays and restaurants will damage the vegetation to a certain extent, destroy the forests that conserve water sources, and reduce the area of secondary forests. In addition, the Longji Terraces Scenic Spot has long rainy seasons and heavy rainfall, terraces collapse and soil erosion. The phenomenon is serious.

\subsubsection{Land use}

Land use will affect the discharge and spread of pollutants, and will have a significant impact on river water quality [8]. There is a certain relationship between land use and landscape pattern and ecosystem services. The type of land use will affect the energy flow and material circulation in the ecosystem. At the same time, the intensity of land use affects ecosystem services. The stronger the human disturbance, the more serious the land degradation. Land degradation will affect the river environment, and river water quality will also change.

The Longji Terraces have a novel and unique construction model, which has successfully avoided various large-scale disasters. However, with the continuous development of tourism, the people of Longji terraces began to build hotels and restaurants on a large scale. The excessive discharge of domestic garbage and sewage and the increase in the abandonment of terraces. The abandoned terraces cannot be repaired, nutrients are lost, and they are easy to collapse in the rainy season. The land area is wasted and the land utilization rate is low. The desolation of terraces and the destruction of vegetation have affected land use. The land use type of Longji terraces is mainly cultivated land, but due to continuous reclamation and destruction, the per capita cultivated land has reached 0.067 ha. According to this situation, it is currently necessary to return farmland to forest to reduce damage. 


\subsection{Construction of water conservancy projects}

Reservoir, as a kind of water conservancy engineering facility, is mainly used to prevent floods and droughts, regulate water flow, store water during wet periods, and release water during dry periods is its main responsibility. Reservoirs can allocate water resources reasonably, but the construction of the reservoir will change the water quality of the river and increase the salinity of the water. The temperature of the water in the reservoir is higher than the surface water in winter and lower than the surface water in summer; and the reservoir is used for flood control and water storage In the process, it is easy to cause eutrophication of the water body and deteriorate the water resources of the reservoir.

There is one Yulan Reservoir in the scenic area, with an effective storage capacity of $205,000 \mathrm{~m} 3$. The reservoir is located in the Ping'an Zhuang Terraced Field Viewing Area, Pingan Village, Longji Terrace Scenic Area, which balances the problem of water resource allocation in the scenic area. Yulan Reservoir needs the construction of cement pavement at this stage, and it is in the process of pavement construction. It will cause the cement to flow into the river and affect the water quality. After the river reaches the downstream, the self-purification capacity of the downstream water body is relatively weakened, and a small amount of non-point source pollutants will enter the river during the rainy season, and the water quality will also change accordingly. Human beings have pros and cons to constructing reservoirs, and they also have a certain impact on the water quality of rivers.

\section{Conclusion and outlook}

Based on the research results of the predecessors, through the analysis of various factors that affect the material and energy flow of the river, how these activities affect the material and energy of the river by changing the material flow, energy conversion and the physical and chemical characteristics of the river water quality. Based on changes in land use and vegetation coverage, the establishment of reservoirs and the behavior of indigenous peoples and tourists themselves, there are various processes that affect the energy flow and material circulation of the water environment. The changes in the flow of material and energy in the river reflect the impact on the material in the river. Causes of energy flow and migration. Starting from the Longji Terraces Scenic Area, this article analyzes the reasons why the scenic spots affect the material and energy of the river, resolves water conflicts for the scenic area, realizes the cooperation in scientific water use, water circulation, and water resource allocation, and realizes the scientific, reasonable and green Longji Terraces Scenic Area Sustainable development provides theoretical support for local decision-makers.

For scenic spots formed by ethnic minority villages in China, the change of river material energy in scenic spots is a concrete study. Through analysis and study of changes in river material energy in different periods and conditions, human activities in scenic spots can be reasonably regulated. The development of the scenic spot plays a very good role and is a good medicine to realize the continuous and sustainable development of the scenic spot. By transitioning from the analysis of the general environment to the study of specific aspects, it is possible to adapt measures to local conditions and better integrate the local environment to promote the development of tourism. It also provides reference and guidance for human activities in scenic spots formed by ethnic minority gathering places across the country.

\section{Acknowledgments}

Supported by:Research and Demonstration of Key Technologies for Sustainable Utilization of Karst Landscape Resources in the Lijiang River Basin (2019YFC0507500)

Supported by:Major Special Project of Guilin Scientific Research and Technology Development Plan (20180102-2)

\section{References}

1. H.S.Lu,HHU,(2007)

2. G. A. Best, S. L. Ross. River pollution studies.,(Liverpool University Press, Liverpool. 1977)

3. G.W.Cheng,D.Q.Wang,JGUT,94-98(2002)

4. N.N.Xiao,M.Zhang,B.Feng,REYB,29,900-910(2020 )

5. M.Y.Wang,Z.J.Wu,Y.X.Hou,JGOU,30,52-55(2019)

6. H.Shao,J.Huang,T.Y.Zuo,CASB,27,227-232(2011)

7. H.L.Cao,GUT,(2019)

8. EQE.Xu,CJEA,27,1880-1891(2019)

9. J.Z.Wang,M.Y.Zhang,J.H.Lu,JID, 74-76(2005) 